\title{
Evaluation of Nitric Oxide Formation from Nitrates in Pig Coronary Arteries
}

\author{
Yoko Aniya $^{1,2, *}$, Naoko Uehara ${ }^{1}$, Chiho Ishii ${ }^{1}$, Tuyoshi Suenaga ${ }^{1}$, Naomi Wada ${ }^{1}$, \\ Toshihiro Matsuzaki ${ }^{3}$ and Matao Sakanashi ${ }^{2.3}$ \\ 'Laboratory of Physiology and Pharmacology, School of Health Sciences, ${ }^{2}$ Research Center of Comprehensive Medicine, ${ }^{3}$ Department \\ of Pharmacology, School of Medicine, Faculty of Medicine, University of the Ryukyus, 207 Uehara, Nishihara, Okinawa 903-01, Japan
}

Received December 11, 1995 Accepted March 5, 1996

\begin{abstract}
To clarify the hypothesis that organic nitrates are converted to nitric oxide (NO) via nitrite ion $\left(\mathrm{NO}_{2}{ }^{-}\right)$by glutathione $S$-transferase, the metabolic conversion of four nitrates was examined in pig coronary arteries and compared with that in rat liver. Nitrates caused the relaxation of the artery muscles with the order of nitroglycerin $>$ isosorbide dinitrate $>$ nicorandil $\geqq$ nipradilol, whereas the order of NO formation in the arteries was nitroglycerin $>$ isosorbide dinitrate $>$ nipradilol $>$ nicorandil. The same order of NO formation from the nitrates was also observed in liver cytosol. Nicorandil may cause more relaxation than nipradilol by both NO releasing and other (unknown) actions. Although the order of the potency in $\mathrm{NO}_{2}$ formation from the nitrates in liver cytosol was the same as that seen in NO formation, $\mathrm{NO}_{2}{ }^{-}$was not detected in pig coronary arteries. Thus $\mathrm{NO}_{2}$ formation from the nitrates correlated with NO formation in liver cytosol but not in pig arteries. When nonenzymatic and enzymatic NO formations from nitroglycerin were examined in the arteries, the enzymatic NO formation, which was not inhibited by glutathione $S$-transferase inhibitors, was $13 \%$ of the total NO. These results indicate that in pig coronary arteries, nitrates release NO mostly through a nonenzymatic manner, although there is a slight amount of enzymatically produced NO, and glutathione $S$-transferase may not contribute to the enzymatic NO formation.
\end{abstract}

Keywords: Nitrate, Nitric oxide, Glutathione $S$-transferase, Vasorelaxation

Nitrate compounds such as nitroglycerin cause relaxation of vascular smooth muscles and thereby have been used for the treatment of angina pectoris. It is generally accepted that the nitrate is converted to nitric oxide (NO) which can activate soluble guanylate cyclase, resulting in accumulation of cGMP followed by muscle relaxation (1). However, the metabolic conversion of nitrates to NO is not well-established. Although glutathione $S$-transferase was believed to be involved in the biochemical process of the relaxation $(2,3)$, evidence shows that the enzyme can catalyze a denitration from nitrates $\left(\mathrm{NO}_{2}{ }^{-}\right.$ formation) but all $\mathrm{NO}_{2}{ }^{-}$thus formed are not converted to NO (4-6) and that there are NO-forming enzymes distinct from glutathione $S$-transferase $(7,8)$. In addition, a nonenzymatic liberation of NO from organic nitrates was reported $(9,10)$. Recently, we demonstrated that nitroglycerin can cause a relaxation of pig coronary arteries despite of depletion of glutathione in the artery, indi-

*To whom correspondence should be addressed ${ }^{(1)}$. cating that glutathione and glutathione $S$-transferase are not important for nitroglycerin-induced relaxation of the artery (11).

In the present study, we examined NO formation from four nitrates using pig coronary arteries and compared it with that in rat liver. It was demonstrated that NO formation from nitrates is mostly nonenzymatic and the enzymatic NO formation, which may be catalyzed by enzyme(s) other than glutathione $S$-transferase, is less than $20 \%$ of the total NO.

\section{MATERIALS AND METHODS}

\section{Preparation of assay samples}

Hearts removed from pigs at the slaughterhouse were placed in ice-cold Krebs-Henseleit solution and then the coronary arteries were isolated. The collected arteries from the hearts were homogenized in 2 volumes of $0.1 \mathrm{M}$ potassium phosphate buffer ( $\mathrm{pH}$ 7.6) with a polytron homogenizer (Kinematica, Lucerne, Switzerland) for 30 
sec twice with a 30-sec intermittence time and then centrifuged at $9,000 \times \mathrm{g}$ for $30 \mathrm{~min}$ at $4^{\circ} \mathrm{C}$. The supernatant thus obtained was used for the measurement of glutathione $S$-transferase activity and $\mathrm{NO}$ or $\mathrm{NO}_{2}{ }^{-}$formation. In measuring glutathione and cysteine contents, the arteries were homogenized in 2 volumes of $0.1 \mathrm{M}$ phosphate buffer $(\mathrm{pH} 7.0)$.

Rat liver cytosol and microsomes were prepared from nontreated Sprague-Dawley rats as described previously (12).

\section{Measurement of NO}

Enzymatic and nonenzymatic NO formation from nitroglycerin in pig coronary arteries were measured as follows: Nitroglycerin $(0.88 \mathrm{mM})$ was mixed with cysteine $(1 \mathrm{mM}), 9,000 \times g$ supernatant of the arteries and oxyhemoglobin $(2.5 \mu \mathrm{mol})$, and the difference spectrum between the reaction mixture and the reference solution which lacks nitroglycerin was recorded at $37^{\circ} \mathrm{C}$ at the cycling time of 2 min using a spectrophotometer (UV-160A with temperature control unit TCC-240A; Simadzu, Kyoto) according to the method of Feelisch and Noack (9). NO content was calculated from the extinction differ- ence per minute between 401 and $411 \mathrm{~nm}$ using nitroprusside as the standard of NO. The amount of NO determined by this method was termed as total NO. The NO released from the incubation of nitroglycerin with cysteine at $37^{\circ} \mathrm{C}$ without the arteries was designated as a nonenzymatic NO formation. Thus the enzymatic NO formation was determined by subtracting the nonenzymatic NO formation from the total NO. As the standard of NO, sodium nitroprusside $(25 \mathrm{nmol})$ was incubated with cysteine (1 $\mathrm{mM})$ at $37^{\circ} \mathrm{C}$, and the extinction difference from 401 to $411 \mathrm{~nm}$ per minute was used as $25 \mathrm{nmol}$ of NO.

\section{Measurement of enzyme activity and thiol contents}

Glutathione $S$-transferase activity was measured by the method of Habig et al. (13) with 1-chloro-2,4-dinitrobenzene (CDNB) $(1 \mathrm{mM})$ and glutathione ( $1 \mathrm{mM}$ or $5 \mathrm{mM}$ in liver microsomes) as substrates. The transferase activity for nitrates was also determined by measuring nitrite ion $\left(\mathrm{NO}_{2}{ }^{-}\right)$released from the reaction by the method of Habig et al. (13). Briefly, the supernatant from pig coronary arteries, rat liver cytosol or microsomes was incubated with nitrates and glutathione $(5 \mathrm{mM})$ at $37^{\circ} \mathrm{C}$ for 30 min in $0.1 \mathrm{M}$ potassium phosphate buffer $(\mathrm{pH} 7.4)$ at the

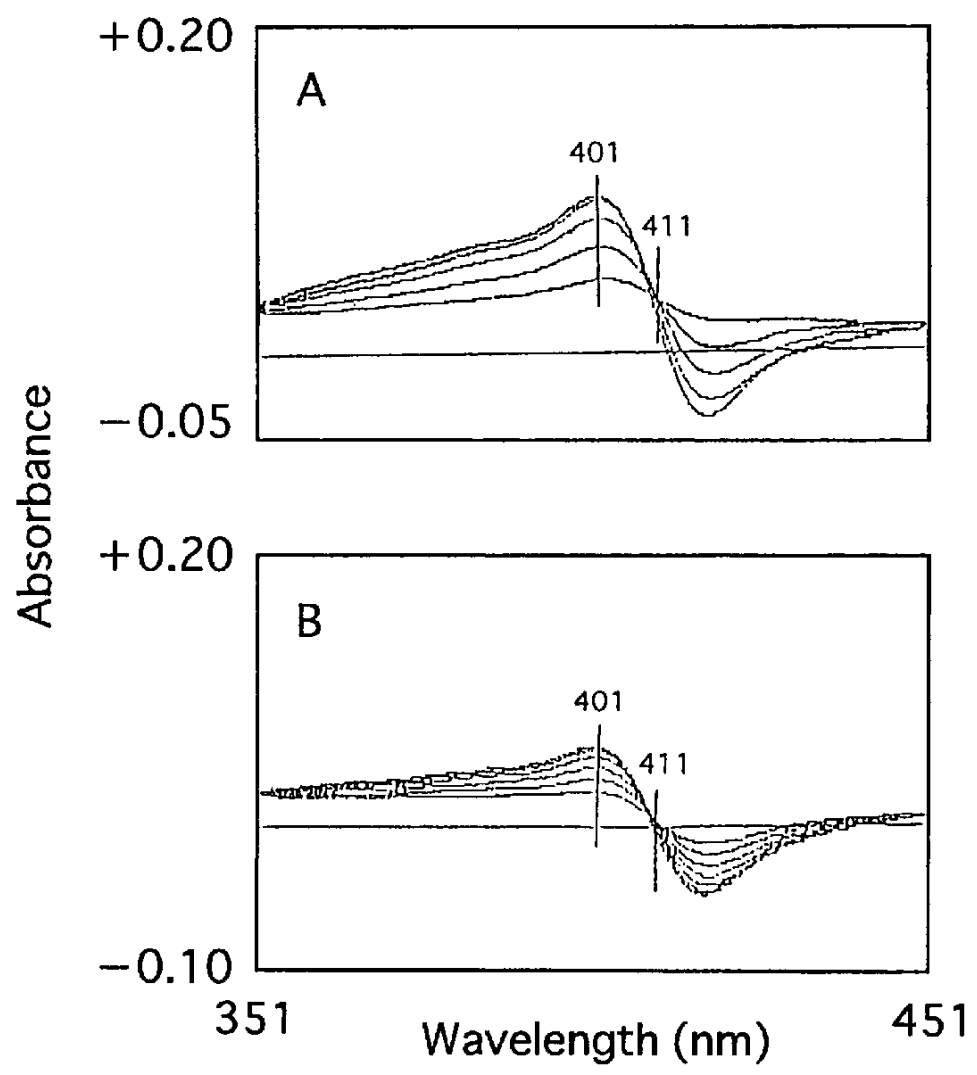

Fig. 1. Difference spectra of oxyhemoglobin versus methemoglobin induced by sodium nitroprusside. Sodium nitroprusside $(25 \mathrm{nmol})$ was incubated at $37^{\circ} \mathrm{C}$ with $1 \mathrm{mM}$ cysteine (A) or glutathione (B) in $0.1 \mathrm{M}$ potassium phosphate buffer (pH 7.6 ) in the presence of $2.5 \mu \mathrm{mol}$ oxyhemoglobin. The difference spectrum from 351 to $451 \mathrm{~nm}$ was recorded at the cycling time of $30 \mathrm{sec}$. 
total volume of $2.0 \mathrm{ml}$. An aliquot was removed at the indicated times and incubated with $0.2 \%$ sulfanilamide and $0.02 \% \mathrm{~N}$-(1-naphthyl) ethylene diamine dihydrochloride (NEDD) at $25^{\circ} \mathrm{C}$ for $20 \mathrm{~min}$ followed by measuring the absorbance at $540 \mathrm{~nm}$. Cysteine and glutathione contents in the homogenates of coronary arteries were determined using a high performance liquid chromatography (CCPM; Toyo Soda, Tokyo) according to the method of Reed et al. (14). Protein concentration was measured by the method of Lowry et al. (15).

\section{Relaxation of pig coronary arteries}

The proximal part of the left circumflex coronary artery with endothelium was cut into ring preparations that were then suspended in organ baths filled with KrebsHenseleit solution maintained at $37^{\circ} \mathrm{C}$ and gassed with $95 \% \mathrm{O}_{2}-5 \% \mathrm{CO}_{2}$. After contraction of the artery ring with $30 \mathrm{mM} \mathrm{KCl}$, each nitrate was added cumulatively to the bath, and the relaxation of the artery muscle was measured as described previously (11).

\section{Chemicals}

1-Chloro-2,4-dinitrobenzene (CDNB), hemoglobin, reduced glutathione, sodium nitroprusside and glutathione reductase were purchased from Sigma Chemical Co. (St. Louis, MO, USA). NADPH was obtained from Oriental Yeast (Tokyo); nitroglycerin from Nihon Kayaku (Tokyo); isosorbide dinitrate from Eisai Co., Ltd. (Tokyo); nipradilol from Kowa Co., Ltd. (Tokyo); and nicorandil from Chugai Pharmaceutical Co., Ltd. (Tokyo) were used. All other chemicals used were of analytical grade.

\section{Statistical analyses}

Data are expressed as means \pm S.D. The significance of difference was calculated by Student's $t$-test, where $\mathrm{P}$ values $<0.05$ were taken as significant.

\section{RESULTS}

\section{NO formation and vosorelaxation by nitrates}

When sodium nitroprusside $(25 \mathrm{nmol})$ was mixed with cysteine or glutathione, a time-dependent increase in the extinction differences between 401 and $411 \mathrm{~nm}$ was observed (Fig. 1). The extinction difference from glutathione was about one fourth that of cysteine. Thus the extinction difference obtained from $25 \mathrm{nmol}$ nitroprusside and $1 \mathrm{mM}$ cysteine was used for the calculation of NO formed from nitrates. In mixing nitroglycerin with the indicated concentrations of cysteine or glutathione, nonenzymatic NO formation was increased with the increase in the thiol concentrations and NO from the cysteine was fivefold higher than that of glutathione

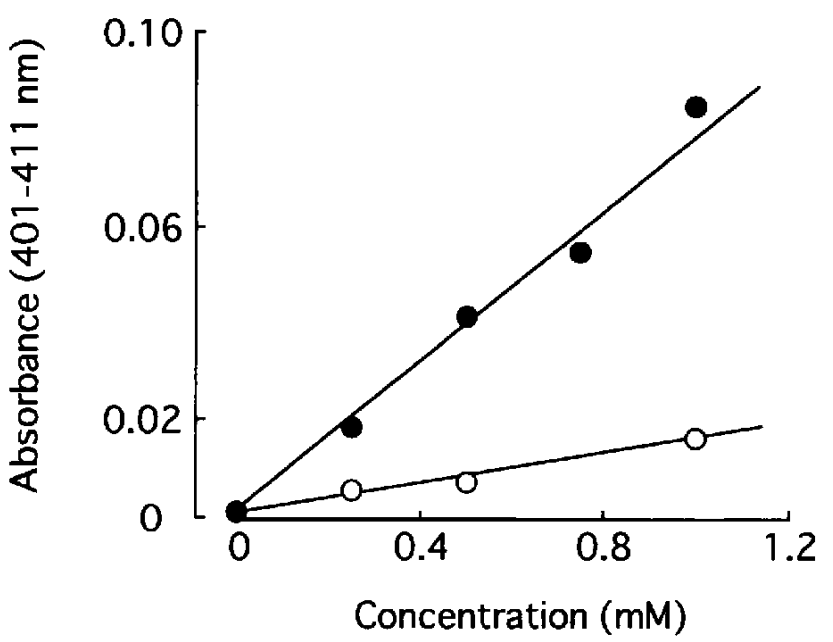

Fig. 2. Nonenzymatic NO formation from nitroglycerin. Nitroglycerin $(0.88 \mathrm{mM})$ was incubated with various concentrations of cysteine $(O)$ or glutathione $(O)$ at $37^{\circ} \mathrm{C}$ in $0.1 \mathrm{M}$ potassium phosphate buffer ( $\mathrm{pH} 7.6)$ in the presence of oxyhemoglobin $(2.5$ $\mu \mathrm{mol})$ and the extinction difference between 401 and $411 \mathrm{~nm}$ was measured. Each point shows the mean of two separate experiments.

(Fig. 2). As shown in Fig. 3, the enzymatic NO formation from nitroglycerin in coronary arteries was only $13 \%$ of the total NO, and thus it was clarified that most of the NO was formed nonenzymatically from nitroglycerin. Enzymatic and nonenzymatic NO formations from four nitrates were determined (Table 1). When the nitrates were incubated with cysteine and coronary arteries, NO was detected as total $\mathrm{NO}$ in the order of nitroglycerin > isosorbide dinitrate $>$ nipradilol $>$ nicorandil, although

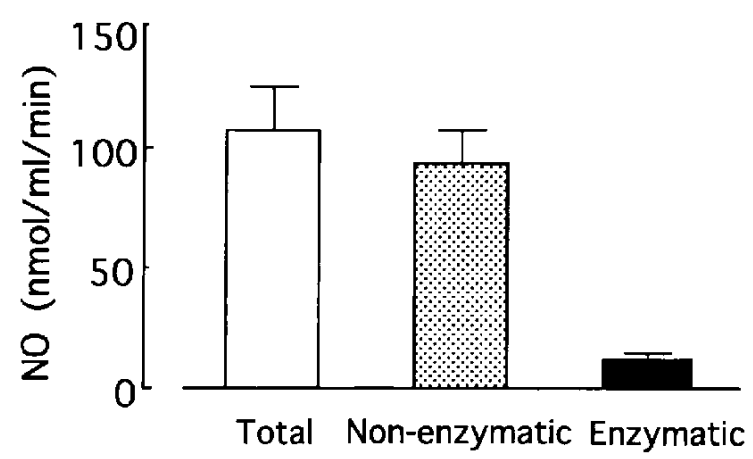

Fig. 3. NO formation from nitroglycerin in pig coronary arteries. Nitroglycerin $(0.88 \mathrm{mM})$ was incubated with cysteine $(1 \mathrm{mM})$ at $37^{\circ} \mathrm{C}$ in the presence (for total NO formation) or absence (for nonenzymatic NO formation) of the supernatant obtained from centrifugation of pig coronary artery homogenates and the difference spectra were recorded. Enzymatic NO formation was calculated by subtracting nonenzymatic NO from total NO as described in Materials and Methods. Each column shows the mean \pm S.D. from three separate experiments. 
Table 1. NO formation from nitrates in pig coronary arteries

\begin{tabular}{lccc}
\hline \multirow{2}{*}{ Nitrates (mM) } & \multicolumn{2}{c}{ NO (nmol/mg/min) } \\
& & Total-NO & Enzymatic-NO \\
\hline NTG & $(0.88)$ & $81.20 \pm 10.7$ & $11.45 \pm 2.3$ \\
ISDN & $(5.0)$ & $41.81 \pm 10.8$ & ND \\
NP & $(10.0)$ & $27.52 \pm 4.0$ & ND \\
SG-75 & $(10.0)$ & $15.14 \pm 1.7$ & ND \\
\hline
\end{tabular}

Each nitrate at the indicated concentration was incubated at $37^{\circ} \mathrm{C}$ with cysteine (same concentration as each nitrate) in the presence or absence of the supernatant from pig coronary arteries. Total and enzymatic NO formation were determined as described in Materials and Methods. Each value shows the mean \pm S.D. for three experiments. NTG, nitroglycerin; ISDN, isosorbide dinitrate; NP, nipradilol; SG-75, nicorandil. ND, not detected.

the nitrate concentration was different in each case. The amount of nonenzymatically formed-NO from each nitrate was almost same as the total NO except for that in the case of nitroglycerin, showing that the NO is formed from the three nitrates nonenzymatically.

Figure 4 shows the nitrate-induced relaxation of the coronary arteries. The median effective concentration (M) for the relaxation was $(2.44 \pm 0.30) \times 10^{-7}$ (nitroglycerin), $(3.05 \pm 0.47) \times 10^{6}$ (isosorbide dinitrate), $(8.56 \pm 1.09) \times$ $10^{-6}$ (nicorandil) and $(1.98 \pm 0.58) \times 10^{-5}$ (nipradilol). Thus the order of the potency of the relaxation did not agree with the order of NO formation in the cases of nipradilol and nicorandil.

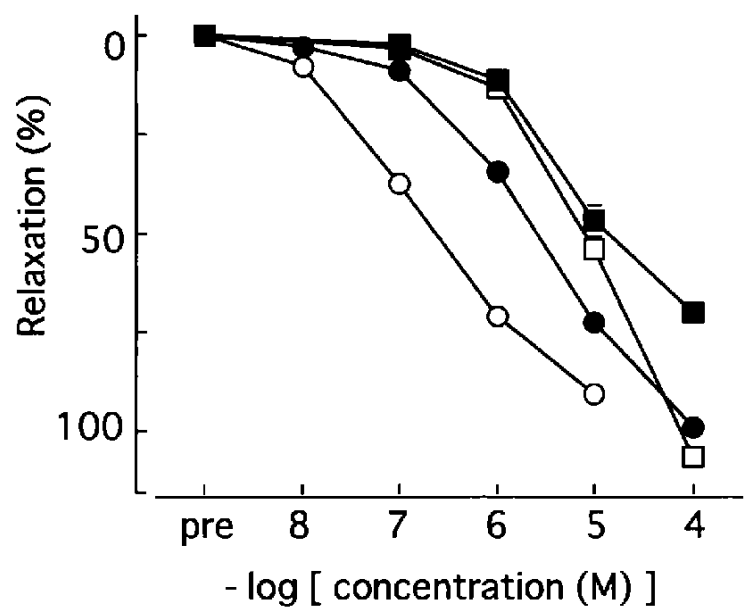

Fig. 4. Concentration-response curves of pig coronary artery rings to nitrate-induced relaxation. After contraction of the artery ring by $30 \mathrm{mM} \mathrm{KCl}$, each nitrate was added cumulatively, and the relaxant response to the nitrate was represented as the percentage relaxation. Each point shows a mean percentage relaxation $(n=7-14)$ with S.E. of potassium-induced tone. When S.E. is not indicated, its value falls within the symbol. $\bigcirc$, nitroglycerin; $O$, isosorbide dinitrate; E, nicorandil; $\mathbf{0}$, nipradilol.
Table 2. Effects of glutathione $S$-transferase (GST) inhibitors on NO formation and GST activity in pig coronary arteries

\begin{tabular}{llc}
\hline Treatment & $\begin{array}{c}\text { Enzymatic-NO } \\
(\mathrm{nmol} / \mathrm{mg} / \mathrm{min})\end{array}$ & $\begin{array}{c}\text { GST activity } \\
(\mathrm{nmol} / \mathrm{mg} / \mathrm{min})\end{array}$ \\
\hline Control & $14.95 \pm 1.9(100)$ & $33.83 \pm 1.1 \quad(100)$ \\
ECA $^{1)}$ & $17.16 \pm 3.2(115)$ & $7.41=1.7^{* * *}(22)$ \\
Control $_{\text {S-Hex }}^{2)}$ & $10.88 \pm 1.9(100)$ & $24.59 \pm 3.0 \quad(100)$ \\
\hline
\end{tabular}

${ }^{1)}$ Pig coronary artery segments were preincubated with ethacrynic acid (ECA, $1 \mathrm{mM}$ ) at $37^{\circ} \mathrm{C}$ for $60 \mathrm{~min}$ and after repeated rinses, the segments were homogenized following by centrifugation. Enzymatic NO formation and GST activity in the supernatant were measured. ${ }^{29}$ Enzymatic NO formation and GST activity were measured after the incubation of the coronary artery supernatant, which was prepared from nontreated arteries, with or without $0.5 \mathrm{mM} S$-hexylglutathione (S-Hex) at $25^{\circ} \mathrm{C}$ for $5 \mathrm{~min}$ as described in Materials and Methods. Each value shows the mean $\pm S$.D. for three experiments. $* * * \mathbf{P}<0.001$, vs control.

Effect of glutathione S-transferase inhibitors on NO formation

Table 2 shows the effects of glutathione $S$-transferase inhibitors on NO formation from nitroglycerin and the transferase activity for CDNB of coronary arteries. When ethacrynic acid was preincubated with the arteries, glutathione $S$-transferase activity was decreased to $22 \%$ of the control, but the enzymatic NO formation was not changed. Similarly, a marked decrease in the transferase activity without change of the NO formation was observed by the incubation of the $9,000 \times \mathrm{g}$ supernatant of coronary arteries with $S$-hexylglutathione.

Formation of $\mathrm{NO}_{2}^{-}$and glutathione S-transferase activity

Tables 3 and 4 indicate the glutathione $S$-transferase activity in pig coronary arteries, liver cytosol and microsomes using nitrates and CDNB as substrates. Glutathione $S$-transferase activity for CDNB was highest in rat liver cytosol, and the activity in the pig coronary artery was less than $3 \%$ of that in the cytosol. The liberation of $\mathrm{NO}_{2}{ }^{-}$from nitrates was observed in the liver cytosol in the order of nitroglycerin $\gg$ isosorbide dinitrate $>$ nipradilol > nicorandil; However, it was not detected in pig coronary arteries. In liver microsomes, glutathione $S$-transferase activity for CDNB accounted for $5 \%$ of that in the cytosol, and $\mathrm{NO}_{2}{ }^{-}$formation was observed only from nitroglycerin and isosorbide dinitrate. The order of the potency for total NO formation from the four nitrates in the liver cytosol was the same as that seen for $\mathrm{NO}_{2}{ }^{-}$liberation in the fraction. 
Table 3. NO and $\mathrm{NO}_{2}^{-}$formation from nitrates

\begin{tabular}{|c|c|c|c|c|c|}
\hline \multirow[b]{2}{*}{ Nitrates } & \multirow[b]{2}{*}{$\mathrm{mM}$} & \multicolumn{3}{|c|}{$\mathrm{NO}_{2}$} & \multirow{2}{*}{$\begin{array}{l}\mathrm{NO}^{1)} \\
\text { Liver } \\
\text { cytosol }\end{array}$} \\
\hline & & $\begin{array}{c}\text { Coronary } \\
\text { arteries }\end{array}$ & $\begin{array}{c}\text { Liver } \\
\text { cytosol }\end{array}$ & $\begin{array}{c}\text { Liver } \\
\text { microsomes }\end{array}$ & \\
\hline & & \multicolumn{4}{|c|}{$(\mathrm{nmol} / \mathrm{mg})$} \\
\hline NTG & 0.88 & ND & $1,116.0$ & 38.6 & 206.7 \\
\hline ISDN & 1 & ND & 67.9 & 96.1 & 22.0 \\
\hline NP & 1 & ND & 34.2 & ND & 4.0 \\
\hline SG-75 & 1 & ND & 7.8 & ND & 2.8 \\
\hline
\end{tabular}

Formation of $\mathrm{NO}_{2}{ }^{-}$in all fractions and "the enzymic NO formation in liver cytosol were determined as described in Materials and Methods. Each value shows the mean of two or three independent experiments. NTG, nitroglycerin; ISDN, isosorbide dinitrate; NP, nipradilol; SG-75, nicorandil. ND, not detected.

Table 4. Glutathione $S$-transferase (GST) activity in pig coronary arteries, liver cytosol and microsomes

\begin{tabular}{lr}
\hline Fraction & $\begin{array}{c}\text { GST activity } \\
(\mathrm{nmol} / \mathrm{mg} / \mathrm{min})\end{array}$ \\
\hline Pig coronary arteries & $32.1 \pm 4.2$ \\
Liver cytosol & $1,323.0 \pm 98.0$ \\
Liver microsomes & $67.9 \pm 7.6$ \\
\hline
\end{tabular}

Each value is the mean \pm S.D. of three independent experiments.

\section{Thiol contents in coronary arteries}

As shown in Table 5, the cysteine content in pig coronary arteries was a fourteenth of the glutathione in the control and was decreased significantly after the incubation of the arteries with nitroglycerin for $60 \mathrm{~min}$ at $37^{\circ} \mathrm{C}$. The glutathione content in the arteries was not altered even after the incubation with nitroglycerin. When the arteries were preincubated with $N$-acetylcysteine $(0.5$ $\mathrm{mM}$ ), a eightfold increase in cysteine content in the arteries, but no increase in glutathione content, was observed.

Table 5. Cysteine and glutathione contents in pig coronary arteries after incubation with nitroglycerin or $N$-acetylcysteine

\begin{tabular}{|c|c|c|c|c|c|}
\hline \multirow{2}{*}{ Treatment } & \multirow{2}{*}{$\mathbf{n}$} & \multicolumn{2}{|c|}{ Cysteine } & \multicolumn{2}{|c|}{ Glutathione } \\
\hline & & $(\mathrm{nmol} / \mathrm{mg})^{1)}$ & $(\mathrm{nmol} / \mathrm{g} . \mathrm{t} .)^{2)}$ & $(\mathrm{nmol} / \mathrm{mg})^{1)}$ & $(\mathrm{nmol} / \mathrm{g} . \mathrm{t} .)^{2)}$ \\
\hline Control & 4 & $0.23 \pm 0.04$ & $16.87=2.3$ & $3.12 \pm 0.2$ & $230.35 \pm 41.8$ \\
\hline NTG & 4 & $0.17 \pm 0.04^{*}$ & $13.11 \pm 2.7^{* *}$ & $3.26 \pm 0.4$ & $238.46 \pm 38.3$ \\
\hline $\mathrm{NAC}+\mathrm{NTG}$ & 2 & 1.92 & 135.90 & 2.83 & 219.48 \\
\hline
\end{tabular}

Pig coronary artery segments were preincubated with nitroglycerin (NTG, $0.5 \mathrm{mM}$ ) in the absence or presence of $N$-acetylcysteine (NAC, $0.5 \mathrm{mM}$ ) at $37^{\circ} \mathrm{C}$ for $60 \mathrm{~min}$ followed by rinsing out the drugs. Cysteine and glutathione contents in the artery homogenates were measured as described in Materials and Methods. Each value shows the mean \pm S.D. ${ }^{*} \mathrm{P}<0.05,{ }^{* *} \mathrm{P}<0.01$, vs control. ${ }^{1)} \mathrm{nmol} / \mathrm{mg}$ protein, ${ }^{2)} \mathrm{nmol} / \mathrm{g}$ tissue.

\section{DISCUSSION}

Studies have indicated that nitrates relax vascular smooth muscles via generation of NO; However, the mechanism of the NO formation was not well established. In the present study, a relationship between NO formation and glutathione $S$-transferase activity was examined with pig coronary arteries, rat liver cytosol and microsomes. When enzymatic NO formation was calculated by subtracting the nonenzymatic NO formation from the total NO, in pig coronary arteries, NO formation from nitroglycerin was mostly nonenzymatic, and only $13 \%$ of the total NO was enzymatically formed. If the supernatant obtained from pig coronary arteries was heated at $100^{\circ} \mathrm{C}$ for $15 \mathrm{~min}$, the enzymatic NO formation was lost (data not shown), confirming that the NO obtained by the subtraction is an enzyme-derived NO. Although nonenzymatic NO formation from nitroglycerin was observed using glutathione instead of cysteine, the amount of NO formed by glutathione was very small. These data suggest that cysteine content in the arteries is more important for NO formation from the nitrate than that of glutathione. Judging from the observation that the enzymatic NO formation in the coronary arteries from nitroglycerin was not changed after the treatment with glutathione $S$-transferase inhibitors, the enzyme does not contribute to the NO formation from the nitrate. Thus the enzymatic NO formation from nitroglycerin is mediated by an enzyme other than glutathione $S$-transferase, and the amount of NO formed in such a manner is small. Although the involvement of glutathione $S$-transferase in NO formation has been suggested $(2,3)$, Ogawa et al. (16) reported that a glutathione-independent enzyme is responsible for denitration of nitrate esters in rabbit liver. It seems that the latter enzyme may be related to NO formation from nitroglycerin.

In our experiments, the relaxation of pig coronary artery muscles caused by the four nitrates showed a good correlation to total NO formation from them except for the case of nicorandil. Although the amount of NO formed from nicorandil was less than that from nipradilol, nicorandil caused more relaxation of the arteries than nipradilol. Though nicorandil acts as $\mathbf{a} \mathrm{K}^{+}$channel opener that causes muscle relaxation $(17,18)$, it has been reported that nicorandil did not hyperpolarize the membrane potential of small coronary arteries of pigs in the presence of over $23.6 \mathrm{mM}[\mathrm{K}]_{\circ}$ (19). Therefore, the result that the relaxation of arteries by nicorandil was greater than that expected from the NO formation level may be due to reasons other than $\mathbf{K}^{+}$-channel opening action. However, in this study, the reason was not clarified. On the whole, the potency of vasomuscle relaxation of the nitrates depends on the amount of NO 
formed.

With regards to NO formation from the four nitrates in pig coronary arteries, NO was formed from $0.88 \mathrm{mM}$ of nitroglycerin, but the same concentration of the other three nitrates did not release NO, and high concentrations ( $5 \mathrm{mM}$ and $10 \mathrm{mM}$ ) of these nitrates were needed for NO formation. Moreover, enzymatic NO formation was observed only in the case of nitroglycerin. To better our understanding of this process, the metabolism of these nitrates in pig coronary arteries was compared with that in rat liver cytosol and microsomes. The mechanism of organic nitrate metabolism is proposed to be as follows $(14,20,21)$ :

$$
\begin{aligned}
\mathrm{RONO}_{2}+\mathrm{GSH} & \rightarrow \mathrm{ROH}+\mathrm{GS}-\mathrm{NO}_{2} \\
\mathrm{GS}-\mathrm{NO}_{2}+\mathrm{GSH} & \rightarrow \mathrm{GSSG}+\mathrm{HNO}_{2} \\
\mathrm{HNO}_{2} & \rightarrow \mathrm{NO}
\end{aligned}
$$

The first step (a) is mediated by glutathione $S$-transferase, and the second step of $\mathrm{NO}_{2}^{-}$formation (b) occurs nonenzymatically. The conversion of $\mathrm{NO}_{2}{ }^{-}$to $\mathrm{NO}$ (c) is caused by an unknown mechanism. We measured $\mathrm{NO}_{2}$ and NO formation from the four nitrates. Although glutathione $S$-transferase activity for CDNB was detected in pig coronary arteries, $\mathrm{NO}_{2}^{-}$was not formed from any of the nitrates in the artery. On the other hand, in the liver cytosol, $\mathrm{NO}_{2}{ }^{-}$and $\mathrm{NO}$ were released with the same order: nitroglycerine $\gg$ isosorbide dinitrate $>$ nipradilol $>$ nicorandil, although the magnitude of NO formation was very small compared with that of $\mathrm{NO}_{2}$. It is therefore assumed that in pig coronary arteries, glutathione $S$ transferase can catalyze glutathione conjugation with CDNB, but little or no nitrate is used as the substrate for the enzyme, whereas in the liver cytosol, the transferase catalyzes denitration followed by NO formation. Considering that glutathione $S$-transferase contributes to $\mathrm{NO}_{2}{ }^{-}$formation from nitroglycerin but not to the NO formation $(6,21)$, it is suggested that nitrates are denitrated by glutathione $S$-transferase in the liver and a part of the $\mathrm{NO}_{2}{ }^{-}$thus formed may be converted to NO, whereas in pig coronary arteries, NO may be mostly formed via a nonenzymatic process.

As nonenzymatic NO formation from nitrates, there is increasing evidence that organic nitrates react with a thiol compound resulting in formation of the unstable intermediate thionitrate (d), which decomposes with the release of $\mathrm{NO}_{2}{ }^{-}$(e) and NO via an intramolecular rearrangement to a sulfenyl nitrite species ( $f, g)(22)$.

$$
\begin{aligned}
& \mathrm{RONO}_{2}+\mathrm{R}^{\prime} \mathrm{SH} \rightarrow \mathrm{ROH}+\mathrm{R}^{\prime} \mathrm{SNO}_{2} \\
& \mathrm{R}^{\prime} \mathrm{SNO}_{2}+\mathrm{R}^{\prime} \mathrm{S}^{-} \rightarrow \mathrm{R}^{\prime} \mathrm{SSR}^{\prime}+\mathrm{NO}_{2} \\
& \mathrm{R}^{\prime} \mathrm{SNO}_{2} \rightarrow \mathrm{R} \mathrm{S}-\mathrm{O}-\mathrm{NO} \rightarrow \mathrm{R} \text { 'S }-\mathrm{NO}
\end{aligned}
$$

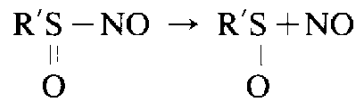

Although all thiols decompose organic nitrates to $\mathrm{NO}_{2}{ }^{-}$, specific thiols such as cysteine and $\mathrm{N}$-acetylcysteine can release $\mathrm{NO}$. Formation of $\mathrm{NO}$ from $\mathrm{NO}_{2}{ }^{-}$, unless there is a specific catalyzing mechanism, occurs only in acidic conditions. It is therefore assumed that $\mathrm{NO}_{2}$ decomposed from organic nitrates is not able to make NO under physiological conditions. In our experiments ( $\mathrm{pH} 7.6$ ), nonenzymatic NO formation from nitrates may come from decomposition of sulfenyl nitrite, not from $\mathrm{NO}_{2}$.

The degree of $\mathrm{NO}_{2}{ }^{-}$and $\mathrm{NO}$ formation from nitrates seems to depend on the number of nitro groups present in the agents because three nitro groups are contained in nitroglycerin, two in isosorbide dinitrate and one in both nipradilol and nicorandil.

In our data, the intracellular concentration of cysteine in the pig coronary artery was confirmed to be only $7 \%$ of the glutathione content, and we could not measure NO from nitroglycerin in the artery without adding cysteine (data not shown). Thus the intrinsic cysteine content in the arteries seems too small to produce NO. However, considering that high concentrations of nitrates are needed for nonenzymatic NO formation in the arteries but low concentrations of nitrates can relax the artery muscles, only a small amount of NO may be enough to produce vasorelaxation. If NO that is locally produced just around guanylate cyclase can activate the enzyme, the small amount of cysteine in the coronary artery may be sufficient for NO formation in vivo. The decrease in the cysteine concentration in pig coronary arteries after treatment with nitroglycerin (Table 5) may reflect a consumption of the cysteine resulting from NO formation in vivo. It has been reported that NO formation from vascular smooth muscle cells was decreased by repeated administration of nitrates (23) and that a decrease in vasorelaxation caused by the repeated treatment with nitrates was restored by a supplementation of thiols $(24,25)$, supporting an important role of cysteine for NO formation and vasorelaxation by nitrates.

In conclusion, in pig coronary arteries, organic nitrates used in the present study form NO mostly by a nonenzymatic manner and only nitroglycerin seems to form NO via an enzymatic process, although the amount of enzymatic NO formation is small. Glutathione $S$-transferase in pig coronary arteries is not involved in the enzymatic NO formation and the cysteine level in the arteries may be critical for NO formation from nitrates.

\section{Acknowledgments}

Isosorbide dinitrate, nipradilol and nicorandil were kindly given to us by Eisai Co., Ltd. (Tokyo), Kowa Co., Ltd. (Tokyo) and Chugai Pharmaceutical Co., Ltd. (Tokyo), respectively. The 
authors thank Ms. N. Murayama for typing the manuscript.

\section{REFERENCES}

1 Ignarro LJ and Kadowitz PJ: The pharmacological and physiological role of cyclic GMP in vascular smooth muscle relaxation. Am Rev Pharmacol Toxicol 25, 171-191 (1985)

2 Yeates RA, Schmid $M$ and Leitold M: Antagonism of glycerol trinitrate activity by an inhibitor of glutathione $S$-transferase. Biochem Pharmacol 38, 1749-1753 (1989)

3 Kenkare SR and Benet LZ: Effect of ethacrynic acid, a glutathione $S$-transferase inhibitor, on nitroglycerin-mediated cGMP elevation and vasorelaxation of rabbit aortic strips. Biochem Pharmacol 46, 279-284 (1993)

4 Feelisch M, Noack EA and Schroder H: Explanation of the discrepancy between the degree of organic nitrate decomposition, nitric formation and guanylate cyclase stimulation. Eur Heart J 9, Supp A, 57-62 (1988)

5 Jakoby WB and Ziegler DM: The enzymes of detoxication. J Biol Chem 265, 20715-20718 (1990)

6 Kurz MA, Boyer TD, Whalen R, Peterson TE and Harrison DG: Nitroglycerin metabolism in vascular tissue: role of glutathione $S$-transferase and relationship between NO and $\mathrm{NO}_{2}{ }^{-}$formation, Biochem J 292, 545-550 (1993)

7 Chung SJ, Chong S, Seth P, Jung CY and Fung H-L: Conversion of nitroglycerin to nitric oxide in microsomes of the bovine coronary artery smooth muscle is not primarily medicated by glutathione-S-transferases. J Pharmacol Exp Ther 260, $652-659$ (1992)

8 Seth P and Fung H-L: Biochemical characterization of a membrane-bound enzyme responsible for generating nitric oxide from nitroglycerin in vascular smooth muscle cells. Biochem Pharmacol 46, 1481 - 1486 (1993)

9 Feelisch $\mathrm{M}$ and Noack EA: Correlation between nitric oxide formation during degradation of organic nitrates and activation of guanylate cyclase. Eur J Pharmacol 139, 19-30 (1987)

10 Noack EA and Feelisch $M$ : Molecular mechanism of nitrovasodilator bioactivation. Basic Res Cardiol 86, Supp 2, $37-50$ (1991)

11 Sakanashi M, Matsuzaki T and Aniya Y: Nitroglycerin relaxes coronary artery of the pig with no change in glutathione content or glutathione $S$-transferase activity. Br J Pharmacol 103, 1905 - 1908 (1991)

12 Aniya $\mathrm{Y}$ and Anders MW: Activation of rat liver microsomal glutathione $S$-transferase by reduced oxygen species. J Biol Chem 264, 1998-2002 (1989)
13 Habig WH, Pabst MJ and Jakoby WB: Glutathione S-transferase. J Biol Chem 249, 7130-7139 (1974)

14 Reed DJ, Babson JR, Beatty PW, Brodie AE, Ellis WW and Potter DW: High-performance liquid chromatography analysis of nanomole levels of glutathione, glutathione disulfide, and related thiols and disulfides. Anal Biochem 106, 55-62 (1980)

15 Lowry $\mathrm{OH}$, Resebrough NJ, Farr AL and Randall RJ: Protein measurement with the Folin phenol reagent. J Biol Chem 193, $265-275$ (1951)

16 Ogawa N, Hirose T, Fukushima $\mathrm{K}$, Suwa $\mathrm{T}$ and Satoh $\mathrm{T}$ : GSH-independent denitration of the nitrate ester of a dehydropyridine derivative in rabbit hepatic cytosol. Biochem Pharmacol 49, $141-146$ (1995)

17 Edwards G and Weston AH: Structure-activity relationships of K -channel openers. Trends Pharmacol Sci 11, 417-422 (1990)

18 Ohta $H$, Jinno $Y$, Harada $K$, Ogawa N, Fukushima $H$ and Nishikori K: Cardioprotective effects of KRN 2391 and nicorandil on ischemic dysfunction in perfused rat heart. Eur $\mathrm{J}$ Pharmacol 204, 171-177 (1991)

19 Furukawa K, Itoh T, Kajiwara M, Kitamura K, Suzuki H, Ito Y and Kuriyama $\mathrm{H}$ : Vasodilating actions of 2-nicotinamidoethyl nitrate on porcine and guinea pig coronary arteries. J Pharmacol Exp Ther 218, 248-259 (1981)

20 Keen JH, Habig WH and Jakoby WB: Mechanism for the several activities of the glutathione $S$-transferases. J Biol Chem 251, 6183-6188 (1976)

21 Hill KE, Hunt RW Jr, Jones R, Hoover RL and Burk RF: Metabolism of nitroglycerin by smooth muscle cells. Involvement of glutathione and glutathione $S$-transferase. Biochem Pharmacol 43, 561 - 566 (1992)

22 Feelisch M: The biochemical pathways of nitric oxide formation from nitrovasodilators: Appropriate choice of exogenous NO donors and aspects of preparation and handling of aqueous NO solutions. J Cardiovasc Pharmacol 17 Supp 3, S25-S33 (1991)

23 Feelisch $\mathrm{M}$ and Kelm M: Biotrasformation of organic nitrates to nitric oxide by vascular smooth muscle and endothelial cells. Biochem Biophys Res Commun 180, 286-293 (1991)

24 Chong $\mathrm{S}$ and Fung H-L: Biochemical and pharmacological interactions between nitroglycerin and thiols. Effects of thiol structure on nitric oxide generation and tolerance reversal. Biochem Pharmacol 42, 1433 - 1439 (1991)

25 Boesgaard S, Petersen JS, Aldershvile J, Poulsen HE and Flachs $\mathrm{H}$ : Nitrate tolerance: effect of thiol supplementation during prolonged nitroglycerin infusion in an in vivo rat model. J Pharmacol Exp Ther 258, 851 - 856 (1991) 